\title{
A Geografia e o Estudo do Ambiente
}

\author{
Geography and Environment Study \\ Luis Antonio Bittar Venturi*1 \\ ${ }^{1}$ Universidade de São Paulo, SP, Brasil
}

\begin{abstract}
Resumo
Este artigo apoia-se em alguns contextos contemporâneos referentes aos conceitos de recursos naturais, através de breve resgate à estrutura do pensamento científico e do estudo do meio ambiente na perspectiva da Geografia. Assim, propomos alguns ajustes conceituais, reforçando a noção de revisibilidade, essencial ao conhecimento científico. Partimos da ideia inicial em que existe um observador e um fato observado, o geógrafo poderá ler este território como espaço, paisagem, região etc (inclusive como território), a depender da teoria que escolha para "ver através de". Esta escolha, obviamente, está relacionada com seu tema de estudo e o enfoque a ele atribuído. Algumas teorias vão valorizar mais a dimensão humana, e em outras, a dimensão ambiental. Isto posto, podemos afirmar que todas as questões ambientais decorrem do ajuste ou desajuste entre as dinâmicas da natureza e da sociedade. Entre as características ambientais mais importantes que influenciam na configuração territorial está a disponibilidade ou não de recursos naturais. A ciência, ao mesmo tempo em que ajuda a transformar o mundo, corre atrás dele para tentar compreendê-lo. Estamos no presente com um olhar para o futuro e outro para o passado. O futuro mostranos novos contextos que nos exigem ajustes conceituais, já que a realidade empírica muda mais velozmente do que o pensamento teórico. O olhar para o passado permite-nos resgatar as estruturas da análise geográfica, integrada, dinâmica e sistêmica, com a qual poderemos compreender os contextos atuais e futuros.
\end{abstract}

Palavras-chave: Conceitos, recursos naturais, Geografia, dinâmicas espaciais, realidade.

\begin{abstract}
This article concern in to draws on some contemporary contexts related to the concepts of natural resources through brief review of the structure of scientific thought and the study of the environment in terms of Geography. Thus, we propose some conceptual adjustments, reinforcing the notion revisibility essential to scientific knowledge. We start from the initial idea that there is an observer and an observed fact, the geographer can read this territory as space, landscape, region etc (including as territory), to depend on the theory that choice to "see through". This choice, of course, is related to their subject and the focus given to it. Some theories will focus more on the human dimension, and in others, the environmental dimension. That said, we can say that all environmental issues arising from adjustment or maladjustment between the dynamics of nature and society. Among the most important environmental features that influence the territorial configuration is availability or not of natural resources. The science, while helping to transform the world, runs after him to try to understand it. We are in this with a look to the future and another for the past. The future shows us new contexts that require the conceptual adjustments, since the empirical reality changes more rapidly than the theoretical thinking. The look to the past allows us to recover the structures of geographic analysis, integrated, dynamic and systemic, with which we can understand the current and future contexts.
\end{abstract}

Keywords: Concepts, natural resources, Geography, spatial dynamics, reality. 


\section{Introdução}

$\mathrm{E}$ ste artigo inicia-se com alguns prolegômenos em que retomamos de forma breve a estrutura do pensamento científico geográfico. Em seguida, situamos o estudo do meio ambiente na perspectiva da Geografia, com exemplos ilustrativos sugerindo como esta temática deve ser tratada por esta ciência.

Entre as questões tratadas pelo estudo do meio ambiente, focalizamos os recursos naturais como tema articulador entre aspectos sociais e físicos que exigem, portanto, uma análise essencialmente geográfica. Em seguida, extrapolamos a análise territorial para além dos recursos, com base em quaisquer aspectos físicos, agora com novos exemplos.

Apoiando-nos em alguns contextos contemporâneos referentes aos recursos naturais, propomos alguns ajustes conceituais, reforçando a noção de revisibilidade, essencial ao conhecimento científico. Em seguida, tecemos algumas considerações finais.

\section{Prolegômenos}

Partimos da ideia inicial em que existe um observador e um fato observado, o que pode ocorrer inclusive no mundo animal. Contudo, se essa observação for intermediada ela se qualifica. Entre as intermediações que se interpõem entre o observador e o fato estão a teoria e o método (auxiliando na organização do raciocínio sobre aquele fato), e as técnicas (auxiliando na obtenção e sistematização dos dados daquele fato observado). Neste momento, em que esta relação passa a ser sistemática e intencional, o observador torna-se um sujeito e o fato um objeto de estudo.

A teoria (do Grego, théa = através + óros = ver $)$ interpõe-se entre o sujeito e o objeto buscando explicá-lo, normalmente por meio de leis e hipóteses que correlacionam fatos aparentemente isolados entre si. Caso esta teoria seja geográfica, este sujeito será um geógrafo, ao passo que o objeto pode ser inicialmente colocado em termos de território formado pela convergência de fatos de duas naturezas: social e natural. Em outras palavras, trata-se de uma combinação entre uma organização social que ocorre sobre uma dinâmica natural. A primeira, movida por valores (culturais, econômicos, sociais) e a segunda por dinâmicas naturais (físicas e bioquímicas).

O geógrafo poderá ler este território como espaço, paisagem, região etc (inclusive como território), a depender da teoria que escolha para "ver através de". Esta escolha, obviamente, está relacionada com seu tema de estudo e o enfoque a ele atribuído. Algumas teorias vão valorizar mais a dimensão humana, e por isso serão mais adequadas a estudos que tenham seu foco nas dinâmicas sociais, a exemplo da teoria do Espaço Geográfico, em que o sistema de ações é mais complexo e dinâmico, enquanto o sistema de objetos, relativamente imutável.
Outras vão valorizar mais os sistemas naturais e serão mais adequadas para estes estudos, a exemplo da Teoria da Paisagem, formada por componentes bióticos, abióticos, enquanto a dinâmica social se resume à ação antrópica. Se, por um lado, as teorias que explicam a natureza se estruturam em leis universais e possibilitam previsões, por outro, as teorias que enfocam a sociedade estruturam-se em conjecturas (ou leis restritas e condicionais) que possibilitam apontar tendências. Portanto, há uma divisão apenas teórico-metodológica, devendo-se resguardar a perspectiva geográfica.

A relação entre estas duas dimensões é ubíqua. Mesmo em longínquos rincões onde a presença humana não é materialmente detectada, há intencionalidades sobre eles (mesmo que voltadas à preservação) que os colocam em uma perspectiva social. A proteção de uma área é uma atribuição de uso que se faz dela, por uma demanda social relacionada à recreação, educação ou para fins científicos. Portanto, mesmo nos ambientes em que não se detecta materialmente a dimensão social, ainda assim, ela existe. Bertha Becker diz que proteger, "(...) sem uso produtivo imediato, é uma forma de controlar o capital natural para o futuro (...)" (BECKER, In: CASTRO, 2009.p.293). Além disso, se considerarmos a existência, de fato, de alterações climáticas globais antropogênicas, qualquer rincão estaria sendo afetado pela ação humana.

A dinâmica social, por ser movida por valores, é mais volátil no tempo e no espaço. O que se pensa hoje acerca do meio ambiente no Brasil é muito diferente do que se pensava na década de 1970. E a posição de protagonismo do Brasil em Nagoya (2010 ou na Rio + 20) foi bem diferente daquela de Estocolmo (1972), quando o Brasil relacionava poluição com desenvolvimento. Quanto à variação dos valores no espaço, o que se pensa hoje acerca do ambiente no Brasil é diferente do que se pensa hoje na China. Ou então, o habitante da metrópole percebe a natureza de modo diferente daquele que vive em áreas rurais, ou das comunidades primitivas.

Por outro lado, a dinâmica da natureza é movida por forças físicas e bioquímicas, mais regulares. Como resultado, as teorias que aludem às questões da natureza baseiam-se em leis universais, de modo que as mesmas leis geomorfológicas que explicam fatos no Brasil poderão ser usadas para explicar fatos em outra região do planeta.

Portanto, é apenas neste sentido, ou seja, pela estrutura das teorias, que as ciências da natureza e da sociedade se diferenciam. As primeiras embasadas em leis universais que podem promover explicações e também previsões, enquanto as segundas, fundamentadas em conjecturas, podem prognosticar tendências. Metodologicamente, os procedimentos são essencialmente semelhantes: a análise integrada de diferentes aspectos (físicos e sociais) situados no tempo e no espaço é a mais forte arma metodológica de todos os geógrafos. Esta análise pode assumir matizes sistêmicas, dialéticas ou fenomenológicas, a depender da base teórica escolhida, a qual, obviamente, deve ser adequada ao tema e à natureza da problemática 
estudada. Mas a base sempre será a análise integrada, podendo ainda derivar-se para a análise comparativa, evolutiva, indutiva etc.

\section{Estudo do meio ambiente na perspectiva da geografia}

Isto posto, podemos afirmar que todas as questões ambientais decorrem do ajuste ou desajuste entre as dinâmicas da natureza e da sociedade. Significa dizer que, no contexto da Geografia, o estudo do meio ambiente está na interface destas duas dimensões e só assim pode ser empreendido. Indo mais além, o estudo do ambiente é essencialmente geográfico; reside no core desta ciência. Os geógrafos ingleses John Mathews e David Herbert sugerem que a geografia se reorganiza não em torno de paradigmas teóricos, (isto seria impossível para uma ciência que se ocupa de um temário infinitamente amplo) mas em torno de temas integradores, entre eles, e principalmente, aqueles voltados ao ambiente, patrimônio e recursos naturais.

Mesmo quando, por exemplo, um impacto possa, por vezes, afetar mais a dinâmica social (contaminação por lixões, como impacto social negativo e reurbanização de favelas, como impacto social positivo), a compreensão destes processos exige uma abordagem geográfica autêntica, ou seja, articulando as dimensões social e natural. Consideremos um exemplo empírico notório: quando ocorre inversão térmica em áreas urbanas e o consequente aprisionamento de poluentes, haverá um impacto negativo ${ }^{1}$ na saúde da população que só poderá ser compreendido se levarmos em conta, por um lado, uma dinâmica atmosférica que gera naturalmente a inversão térmica, sobretudo no inverno e, por outro, uma sobrecarga de poluentes, resultado de um modelo socioeconômico e urbano (lembrando que o que prejudica é o aprisionamento de poluentes e não a inversão térmica como fenômeno climático em si), além de aspectos culturais, como a valorização do transporte individual. A articulação destes aspectos físicos e sociais é empreendida pelo método da análise integrada que poderá gerar uma compreensão ampla e completa de um processo. Tal compreensão poderá, pela sua densidade, subsidiar eficazmente políticas públicas no combate à poluição urbana. Este é apenas um exemplo de como a abordagem geográfica pode produzir, ao articular as dimensões física e social, conhecimentos mais sólidos e completos para subsidiar ações mais efetivas, recomendando ajustes entre a dinâmica social e a natural. Isto requer, no entanto, que o geógrafo dispa-se de preconceitos com determinados temas, sobretudo os de natureza física; do contrário, incorrerá no risco de promover estudos frágeis e incompletos.

1 É conveniente sempre designar se o impacto é negativo ou positivo, para se superar a ideia do senso comum de que é sempre algo negativo.
Os desajustes entre as dinâmicas social e natural podem ser interpretados de diversas maneiras, segundo o aporte teórico. Porém, acreditamos que a visão sistêmica é particularmente dinâmica e integradora. No exemplo dado, haveria uma sobrecarga de matéria e energia (poluição e calor) no sistema (clima urbano) alterando os fluxos e as funções. A visão sistêmica, ainda, adéqua-se às questões ambientais por diferenciar o tempo social do tempo natural. Quase que invariavelmente, a dinâmica social, mais veloz, impõe um ritmo sobre a natureza (na apropriação de recursos, nas descargas de poluentes etc) acima da sua capacidade de absorção, diminuindo sua capacidade de recomposição (de estoques, no caso dos recursos, e de depuração, no caso da poluição). Deste modo, veremos adiante que a renovabilidade dos recursos está, em grande parte, relacionada à sua gestão, além, obviamente, de suas propriedades naturais. Por esta razão, os conceitos que embasam o estudo do ambiente, como impacto, renovabilidade e sustentabilidade carregam em si um grande potencial integrador das dinâmicas físicas e sociais. Voltaremos a este tema adiante.

\section{Os recursos naturais como tema articula- dor das dimensões social e natural}

Entre as características ambientais mais importantes que influenciam na configuração territorial está a disponibilidade ou não de recursos naturais. Este é, talvez, o principal elo entre a dimensão física e social. A relação sociedade-natureza está sempre impressa no território, de forma mais ou menos evidente, não apenas pela apropriação de recursos, mas também por outras características ambientais. Comecemos com os recursos naturais.

Etimologicamente, recurso refere-se algo a que se recorre. Portanto, este termo é imbuído de um conteúdo histórico, já que a demanda por algo pode existir ou deixar de existir ao longo do tempo. Por esta razão Zimmermann (1966) afirmou que os recursos não são, mas se tornam. E o complemento do conceito dado pelo termo natural indica que a ocorrência e distribuição de um recurso no planeta dependem de um conjunto de fatores naturais.

Valorizando-se apenas o aspecto social, o recurso natural se torna um simples dado econômico, perdendo sua dimensão geográfica. $\mathrm{O}$ mesmo ocorre quando se valorizam apenas as propriedades naturais do recurso (físicas e bioquímicas), reduzindo-o a um elemento natural. Deste modo, recurso natural é algo que só pode ser compreendido pela articulação destas duas dimensões: social e natural. E a relação entre estas duas dimensões é ubíqua; ocorre em qualquer lugar, qualquer tempo e qualquer escala. Vejamos alguns resultados desta relação intermediada por recursos naturais, em diferentes tempos e escalas, começando por exemplos mais explícitos: 


\subsection{Antigo Egito - escala nacional}

A configuração territorial alongada deriva de um tipo de ocupação essencialmente relacionado à ocorrência de alguns recursos naturais (água e solos férteis) e, ao mesmo tempo, à não ocorrência destes recursos nas áreas adjacentes.

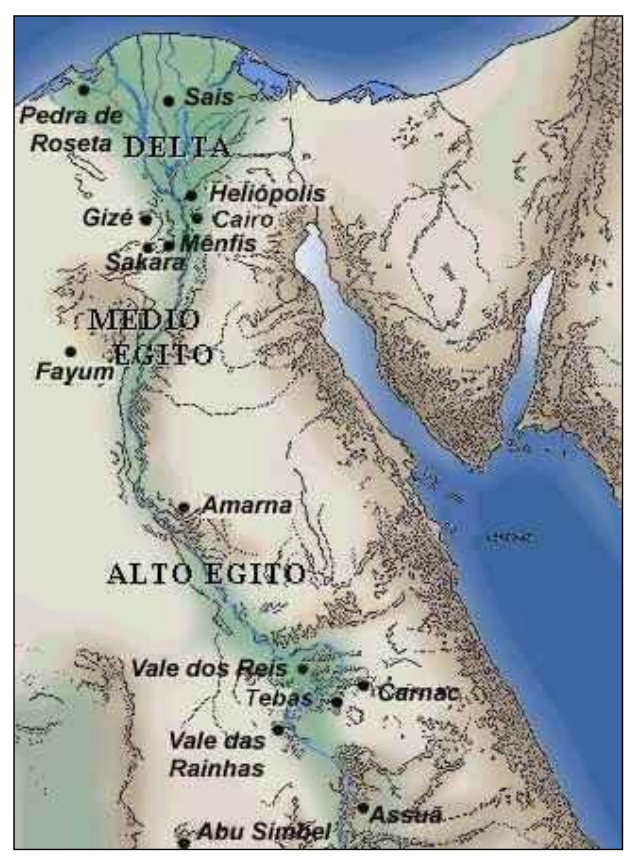

Figura 1 - Ocupação e uso do território no antigo Egito.

Fonte: http://www.google.com.br/imgres

A relação sociedade-natureza tende a ser mais nítida nos contextos de escassez de recursos naturais, como no Egito. Aqui, não se está propondo a ressurreição do determinismo geográfico, mas uma interpretação da paisagem segundo Augustin Berque, que define a paisagem matriz como ativa e passiva. Neste caso ilustrativo, a paisagem seria mais ativa, menos sutil.

Se um dia acreditou-se que a força da natureza se dava pela abundância de recursos (por ter as paisagens brasileiras como principal referência), hoje, parece que a força da natureza que se impõe e se expressa na organização do território advém muito mais da escassez de recursos.

\subsection{América Latina (séc. XIX) - escala conti- nental}

O primeiro aspecto que chama a atenção na configuração territorial da América Latina refere-se ao fato de existir um país de grandes dimensões rodeado por diversas outras nações menores. Quais fatores, além dos históricos, poderiam ser incorporados na análise geográfica para explicar este fato?
A história da América Espanhola está estreitamente relacionada a alguns recursos minerais, como a prata, cuja ocorrência e extração são pontuais. Por isso, as atividades circunscritas às minas favoreceram a formação de núcleos urbanos, o que pode ajudar a explicar por que neste lado do continente a urbanização se desenvolveu mais do que na sua porção oriental. Outro aspecto que pode auxiliar na compreensão desta urbanização refere-se ao relevo e às condições climáticas que, ao contrário da América Portuguesa, desfavoreciam o desenvolvimento de atividades que demandam mais movimentação no território, como o extrativismo, a agricultura e a pecuária. Os núcleos urbanos representam ambientes mais propícios à politização e, consequentemente, a história da América Espanhola é repleta de heróis e movimentos revolucionários que acabaram dando origem a diversas nações.

Na América Portuguesa, a mobilidade territorial foi muito mais intensa dada a natureza dos recursos naturais explorados e ao caráter extrativista da colonização. Ao longo da história colonial, a exploração de recursos florestais (pau-brasil e, mais tarde, a borracha), agrícolas (cana-de-açúcar, café), além da busca pelo ouro exigia grande mobilidade e, consequentemente, uma ocupação humana mais generalizada. Esta mobilidade era favorecida tanto pelo relevo predominantemente aplanado, como pelas densas redes hidrográficas. Este fato certamente contribuiu para a manutenção de uma só nação em uma época em que o domínio exigia a ocupação. Naquele contexto, os movimentos revolucionários da história do Brasil não foram suficientes para ameaçar a integridade nacional. E se considerarmos que um dos mais importantes movimentos ocorreu em uma das regiões mais urbanizadas da colônia (A Inconfidência Mineira, em Vila Rica), e que esta urbanização estava essencialmente ligada à mineração, temos mais uma evidência favorável à hipótese que relaciona recurso mineral com urbanização e com politização social.

\subsection{Amazônia legal (séc. XX) - escala regional}

A ocupação e o uso que avançam sobre o domínio morfoclimático e fitogeográfico amazônico produzem uma configuração territorial a qual, mais uma vez, pode ser explicada pela relação do uso com os recursos naturais disponíveis: a madeira, a floresta e os solos agricultáveis.

O avanço da ocupação viabiliza-se por alguns fatores socioeconômicos e políticos, como a estrutura fundiária, a abertura de estradas e os incentivos fiscais aliados a um fraco controle por parte do poder público.

Por outro lado, o tipo de recurso natural em questão é essencial para explicar a configuração resultante do território. Ao contrário das atividades mineradoras que tendem a concentrar a população, o extrativismo da madeira e dos recursos florestais, como as atividades agrícolas, tendem a promover uma ocupação mais difusa pelo território. 


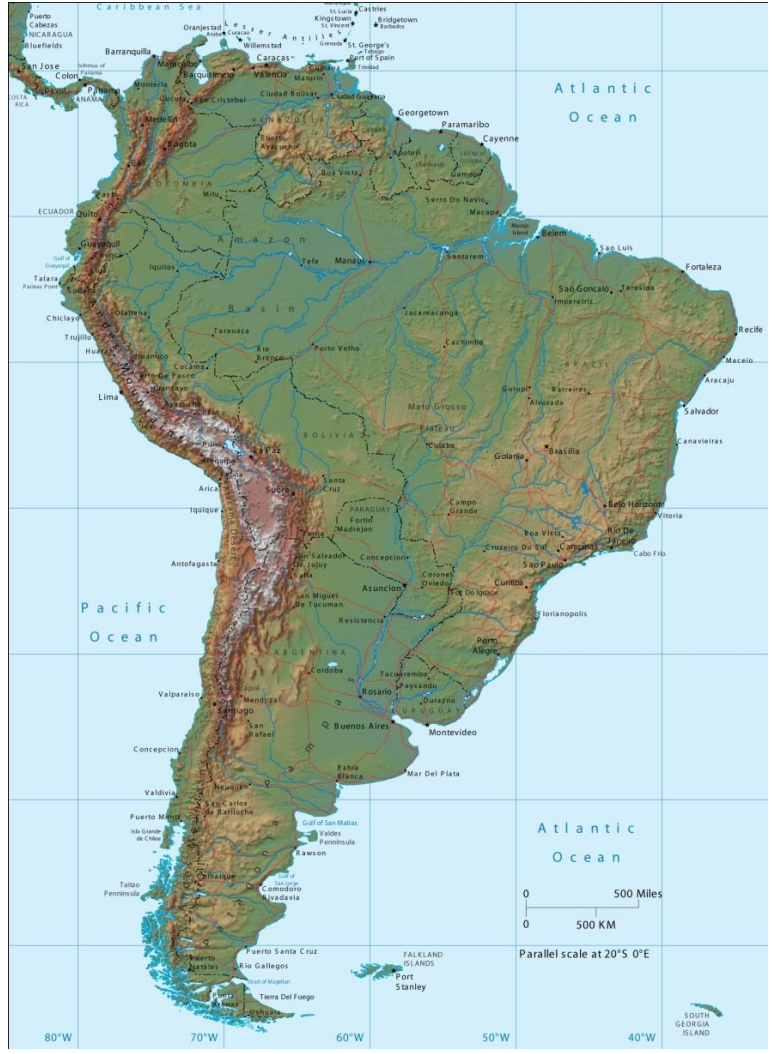

Figura 2 - Configuração territorial da América Espanhola em contraste com a Portuguesa. Relação com recursos naturais e aspectos físicos. Fonte: Atlas Mundial DK.

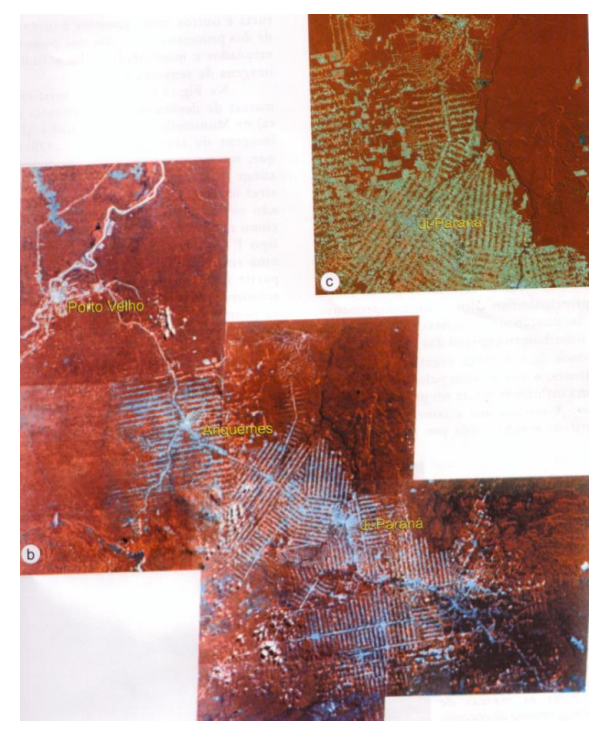

Figura 3 - Imagens TM LANDSAT (1987) mostrando a ocupação de uma região de Rondônia ao longo da rodovia BR364, definindo padrão denominado espinha de peixe. Fonte: FLORENZANO, T.G.

Imagens de satélite para estudos ambientais. São Paulo: Oficina de Textos/INPE, 2002.p.61
Estes fatores sociais e naturais associados resultam numa ocupação do tipo "espinha de peixe" pelas incursões na floresta ao longo das estradas. E a análise geográfica só será completa se forem considerados todos estes fatores mencionados.

\section{4 Áreas costeiras atuais - escala local}

Na escala local, o Geógrafo também vai encontrar diversos contextos em que as dimensões social e natural são indissociáveis; contextos em que a configuração do território é mediada pelos recursos naturais de forma mais nítida ou mais implícita. Tomemos o exemplo emblemático da configuração urbana do município de Praia Grande, no Estado de São Paulo. Que fatores, ou quais variáveis poderiam ser trazidas para a análise integrada e dinâmica (geográfica) de forma a explicar satisfatoriamente este traçado urbano tão peculiar?

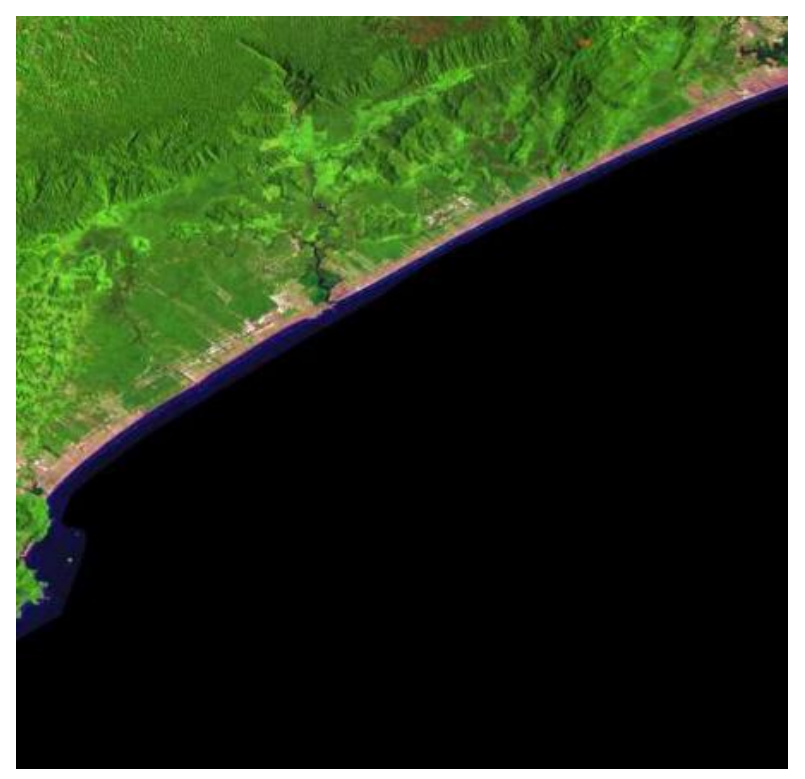

Figura 4 - Imagem TM Landsat da ocupação e uso das áreas costeiras do Estado de São Paulo (Praia Grande).

Fonte: www.embrapa.gov.br

Primeiramente, consideremos a paisagem com vista para o mar como um recurso natural imaterial de aproveitamento indireto. Neste caso, não está ocorrendo uma apropriação direta e material, como estaria no caso da pesca, da navegação etc, mas indireta e imaterial, pois se está apropriando de um aspecto da natureza e não de um elemento natural ${ }^{2}$. Em seguida, temos que considerar que esta apropriação é incentivada por uma

2 Para aprofundar a discussão sobre recursos naturais imateriais de aproveitamento indireto e obter mais exemplos destes casos, ver "Recurso Natural: a construção de um conceito". In: VENTURI, L.A.B. Ensaios Geográficos. São Paulo: Ed. Humanitas, 2009. 
variável cultural. No Brasil, há uma supervalorização da proximidade com o mar, o que não ocorre da mesma maneira em diversas partes do mundo. Complementarmente a esse aspecto cultural, há que se levar em conta uma variável político-econômica que permite este tipo de ocupação no zoneamento urbano e viabiliza a especulação imobiliária. Além do mar, outra variável física poderia ser incorporada nesta análise: a escarpa do planalto que representa uma restrição para a expansão urbana para o interior, associada à atual legislação ambiental que também tenta evitar a ocupação dos setores mais íngremes. Este último aspecto geomorfológico é de importância fundamental à análise geográfica, pois permite explicar, por exemplo, contextos em que todas as outras variáveis estão presentes, mas que não apresentam uma configuração urbana tão marcadamente alongada como a deste exemplo.

\section{Configuração territorial para além dos recursos naturais: novos exemplos}

Na seção anterior argumentamos que meio ambiente (lato senso) não é apenas um tema recorrente da análise geográfica, mas um tema que resgata os fundamentos próprios da geografia. Remete-nos às raízes da ciência geográfica na medida em que nos exige pensarmos sobre o ser humano no mundo. O meio ambiente está 'at heart of debates about the continuing/re-imagined 'unity' of the discipline' (Mathews e Herbert, 2004, p.109). Os autores ingleses propõem que a análise ambiental, da qual os recursos naturais fazem parte, é que pode reunificar a geografia. Dentre esses autores, alguns são mais específicos ainda, afirmando que "Water has been used by many geographers as a unifying topic".

Se esta argumentação foi convincente, então podemos arriscar ir um pouco mais além. Não apenas os recursos influenciam a configuração do território, mas também qualquer característica natural subjacente, cabendo ao geógrafo identificar as relações, nem sempre tão nítidas, da configuração territorial com os aspectos físicos presentes. Vejamos alguns exemplos, iniciando pela cidade de Bogotá, na Colômbia.

O primeiro aspecto que nos chama a atenção neste contexto refere-se ao fato de os edifícios mais altos encontrarem-se à margem do centro da cidade, nas encostas da cordilheira, e não no centro como seria de se esperar de grandes cidades americanas. Um geógrafo desavisado poderia pensar que um novo paradigma urbano estaria sendo criado, contrariando a lógica da valorização do espaço; ou então, que as instituições colombianas seriam fortes o suficiente para impedir a instalação de grandes empreendimentos no centro mais antigo, o que poderia descaracterizá-lo. Estes aspectos não estão descartados, mas seriam de complicada comprovação. Antes de nos lançarmos em conclusões precipitadas devemos analisar a paisagem geográfica mais atentamente, incluindo os aspectos físicos. Neste caso, fatores geológicos e geo-

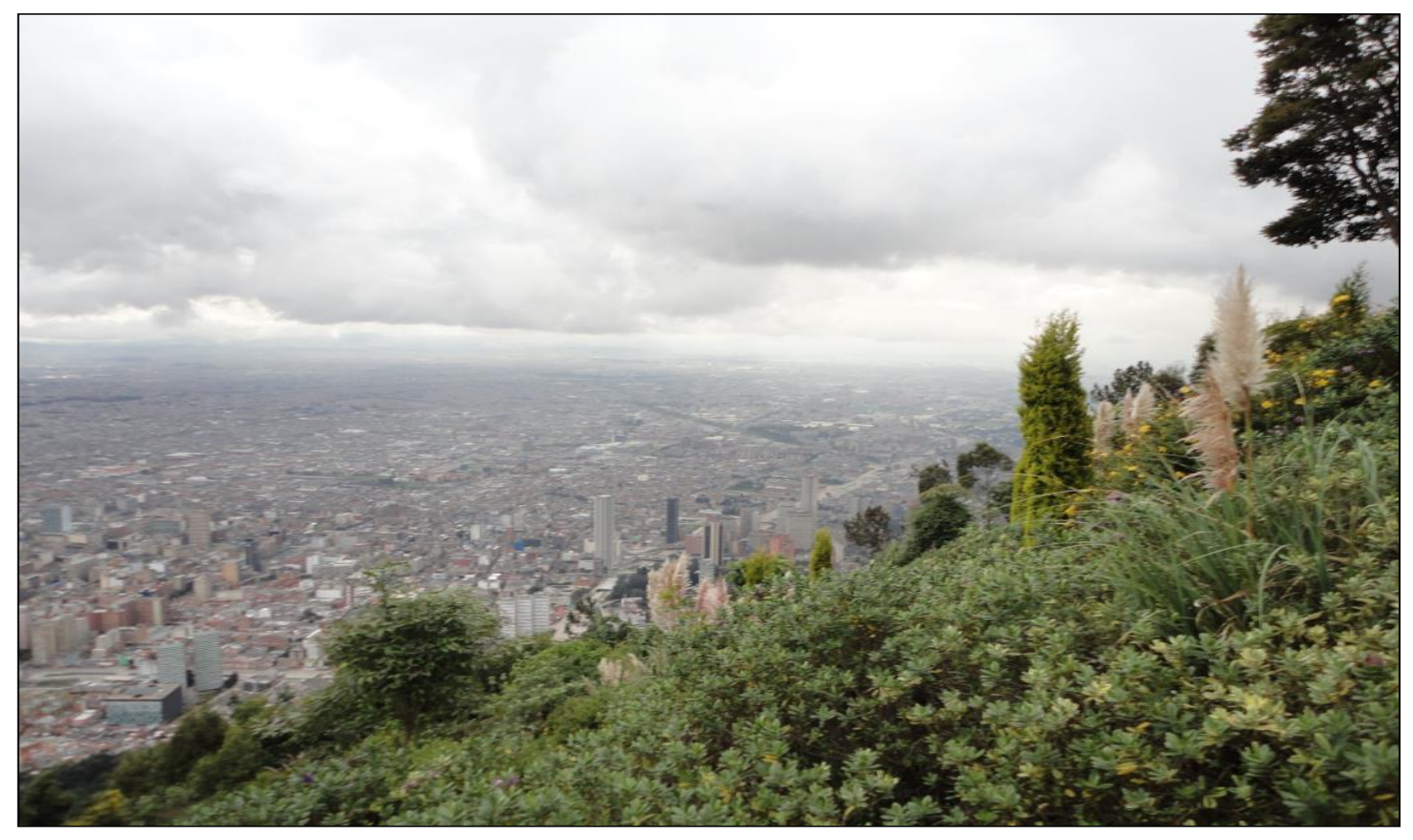

Figura 5 - Cidade de Bogotá (Colômbia) vista do alto do Mont Serrat (Cordilheira dos Andes). Autor: Angela Maria Endlich (2007) 
morfológicos representam variáveis essenciais para a explicação desta configuração urbana. É fácil identificar que existem dois compartimentos distintos nesta paisagem: uma bacia sedimentar sobre a qual a maior parte da cidade está assentada, e um dobramento orogênico (a cordilheira). Sabemos que os dobramentos são compostos de rochas cristalinas, mais resistentes do que as sedimentares. Sabemos ainda que os dobramentos recentes, como os Andes, são áreas suscetíveis de abalos sísmicos. Obviamente, as edificações mais altas do tipo torres serão mais estáveis e resistentes à sismicidade se estiverem sobre rochas cristalinas, ao passo que na área sedimentar, por ser menos consistente, predominam os edifícios do tipo bloco, mais largos e mais baixos. Assim, existe uma relação entre edifícios torre com o ambiente cristalino e os edifícios bloco com o ambiente sedimentar. Eis um novo paradigma urbano que deve ter se originado na cidade do México. Nesta cidade, em 1985, um forte terremoto fez desmoronar muitos edifícios torre que se assentavam na bacia sedimentar, provocando uma alteração radical no mercado imobiliário. Estes elementos físicos são, nestes contextos, capazes de alterar a lógica da valorização do espaço.

Outro exemplo pode ser ilustrado pela RMSP (Região Metropolitana de São Paulo) e RMBS (Região Metropolitana da Baixada Santista). Alguém que desconheça os aspectos geomorfológicos existentes entre estas duas regiões dificilmente compreenderá satisfatoriamente o fato de elas não estarem conurbadas.

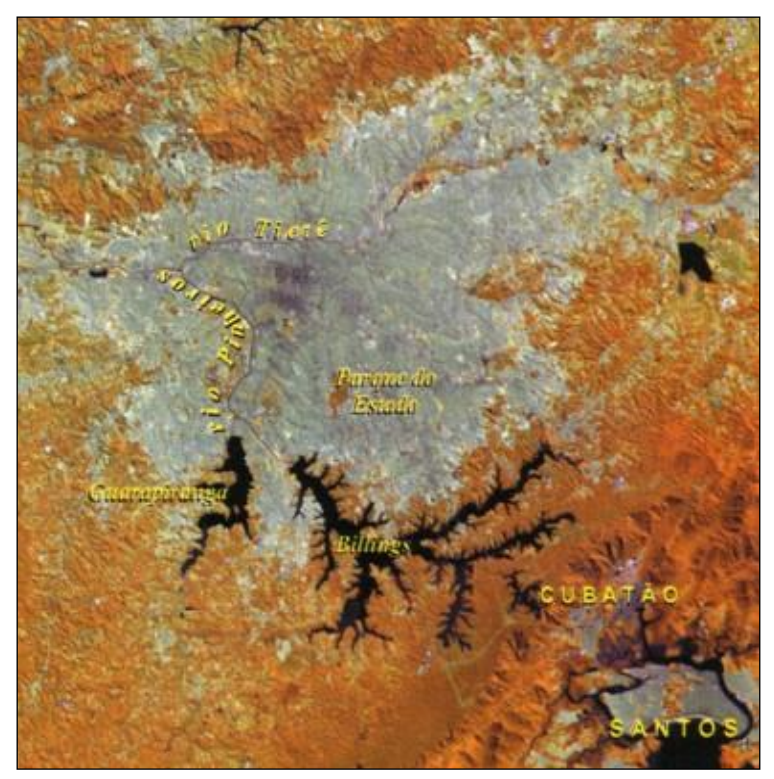

Figura 6 - Imagem de satélite da RMSP e RMBS.

Todas as leis urbanas apontariam para uma conurbação, especialmente aquela que relaciona a expansão urbana com os vetores do sistema viário. Temos entre estas duas regiões o mais complexo e sofisticado sistema viário do país (o Sistema Anchieta-Imigrantes); também temos aí o maior porto do país, vizinho à maior metrópole nacional; tudo isso levaria a um prognóstico de conurbação que, no entanto, não ocorre devido à escarpa tectônica que separa estas duas metrópoles.

Até aqui não há nada de novo. Estamos apenas resgatando a análise geográfica como Vidal de La Blache já fazia e que a perdemos em algum lugar, ou algum 'não-lugar'... Veja o que ele diz no "Préface de l'Atlas Général": La carte politique du pays à étudier est accompagnée d'une carte physique; elles s'eclairent l'une par l'autre $(\ldots)^{3}$. E continua:

“Cette espèce de dossier - que l'on me passe l'expression - constitué, suivant les cas, d'une façon plus au moins complete, a pour but de placer sous les yeux l'ensemble des traits que caractérisent une contrée, afin de permettre à l'esprit d'établir entre eux une liaison." ${ }^{4}$

É o que fazemos ainda hoje: análise integrada. Ou, pelo menos, que deveríamos fazer. É a técnica (representação cartográfica) apoiando o método (análise integrada). Vejam que a ideia do SIG tampouco é nova. Apenas os recursos técnicos nos facilitam estabelecer a "liaison entre les traits". Em seguida ainda La Blache diz: “Ces idées, qui ne saurait paraître une nouveauté qu'à ceux qui auraient oublié les leçons des principaux géographes de notre siècle (...)" $)^{\prime 5}$. Ou seja, para Vidal, a análise integrada de aspectos físicos e sociais já era um paradigma metodológico clássico consolidado e que fora, de certa forma, esquecido por muitos, já naquela época.

Esta lição nos foi repassada e reforçada por Carlos Augusto Figueiredo Monteiro, quando aconselhou que:

[...] os geógrafos dedicados aos aspectos naturais não deixem de considerar o homem no centro deste jogo de relações, e que aqueles dedicados às desigualdades sociais não as vissem fora dos lugares (...). O verdadeiro fio condutor de uma estratégia capaz de promover a unicidade do conhecimento geográfico advirá de um pacto mais profundo que só pode emanar de uma concepção filosófica propícia. (MONTEIRO, 1984. p.24-25)

Deste modo, o que estamos apresentando aqui não é uma nova proposta de análise geográfica, mas um resgate dela e de seus fundamentos metodológicos que nos foram ensinados pelos clássicos.

\footnotetext{
3 A carta política do país a ser estudado é acompanhada de uma carta física; elas se elucidam mutuamente.

4 Esta espécie de dossiê, diga-se de passagem, constituído, de acordo com o caso, de uma maneira mais ou menos completa, tem por finalidade localizar sob os olhos o conjunto das feições que caracterizam uma região, a fim de permitir ao espírito estabelecer uma ligação entre eles.

5 Estas ideias só pareceriam novidade àqueles que esqueceram as lições dos principais geógrafos de nosso século.
} 


\section{Ajustes conceituais necessários à análise geográfica do ambiente: uma perspectiva sistếmica}

A temática ambiental na Geografia é sustentada por uma coleção de conceitos, entre eles o de sustentabilidade, renovabilidade, esgotabilidade e impacto. Aceitando-se o proposto, de que o Estudo do Meio Ambiente deve ser, sob a perspectiva geográfica, abordado pelas dimensões social e natural, alguns ajustes conceituais se fazem necessários.

Aqui focalizamos apenas o conceito de renovabilidade, mas cujos argumentos poderão servir também para os outros conceitos elencados. Costuma-se classificar os recursos em renováveis e não renováveis de forma direta, apenas considerando se são vegetais (renováveis) ou minerais (não renováveis), o que para a análise geográfica é insuficiente. Tomemos o exemplo da cana-de-açúcar que, sob uma visão fragmentada, é normalmente classificada como recurso natural energético renovável. Embora a cana seja, em princípio um recurso vegetal energético renovável, sua produção depende de outro recurso que não o é: o solo. Portanto, numa perspectiva sistêmica, não se pode considerar a cana como renovável, pois depende do solo que se esgotará, a depender do ritmo e tipo de uso que se lhe imponha. Até que a Embrapa desenvolva alguma espécie de 'cana hidropônica', a dependência do solo existirá. Se um dia isto ocorrer, nova revisão conceitual será requerida.

Tomemos agora o exemplo do próprio solo. Não há consenso em relação à renovabilidade dos solos, mas sabe-se que, em determinadas condições ambientais (mais calor e água) os processos bioquímicos são acelerados e, consequentemente, os processos pedogenéticos também. Assim, em determinadas condições naturais, poderia haver formação de pequenos horizontes superficiais de solo na escala de tempo humano. Para que isso ocorra, porém, há que se dar trégua ao solo, ou seja, não se pode impor um ritmo de produção muito intenso a ponto de se fazer necessário cada vez mais insumos para manter a produtividade, até um total esgotamento. Portanto, a renovabilidade do solo depende tanto de características físicas e bioquímicas, como da dinâmica socioeconômica que lhe é imposta. Começamos a perceber que a ideia de uma lista definitiva do que seja recurso natural renovável ou não renovável perde força. Godard (2002, p.207) reforça esta ideia quando afirma que para além das propriedades fundamentais, os recursos não podem ser fixados de uma vez por todas.

Outro fator importante a ser considerado na análise da renovabilidade é o tipo de uso atribuído ao recurso. Se para o uso agrícola o solo pode, em certas circunstâncias, ser considerado esgotável, para outros usos não: quando o solo é usado como matéria bruta para preenchimento de cavas, aterros, correções topográficas, recobrimento de camadas de lixo, enfim, usos "menos nobres", para esses usos não pode ser considerado esgotável, pois é um material praticamente onipresente nos continentes. Outro exemplo: se os recursos orgânicos de um rio podem se esgotar devido à poluição por contaminantes ou pela superexploração, o uso deste mesmo rio como hidrovia pode permanecer indefinidamente enquanto não secar ou não assorear a ponto de impedir a navegação. Neste último caso, ainda, é possível recuperar as condições anteriores mais facilmente.

Em suma, a renovabilidade não pode ser um atributo a priori de um recurso, na medida em que depende dos diversos fatores aqui mencionados. Indo um pouco mais além, outros ajustes conceituais podem ser propostos para aumentar a acurácia do conceito de renovabilidade. Tomemos a definição proposta por Godard (2002): o autor considera como renováveis os recursos que se recompõem naturalmente dentro da escala de tempo humano, o que não é o caso da cana-de-açúcar ou de qualquer agronegócio, silvicultura ou pecuária intensiva, granjas etc. Nestes casos, embora a produção seja baseada em mecanismos naturais, estas dinâmicas são aceleradas para aumentar a produção. Este fato os diferencia essencialmente dos recursos renováveis obrigando-nos a também diferenciá-los conceitualmente. Se aceitássemos a classificação de renovável para a cana-de-açúcar, teríamos que acreditar que extensos canaviais ou extensas áreas cultivadas poderiam existir naturalmente. Portanto, o autor propõe o conceito de recursos reprodutíveis, para designar aqueles que o homem pode reproduzir, como os relacionados à agricultura, mas também aqueles que o homem pode recuperar, como os solos e as florestas. Considerando estes dois últimos exemplos, temos que muitos recursos naturais renováveis poderiam se tornar reprodutíveis quando o homem lhes insere sistemas técnicos para mantê-los ou acelerá-los. A recíproca, no entanto, não é necessariamente verdadeira, já que é muito improvável que exista um canavial natural.

A esta altura podemos nos remeter a duas categorias aristotélicas: a techné (tudo o que é criado pelo homem) e a physis (a natureza, tudo o que existe de forma independente do homem), lembrando que a techné é uma subcategoria da physis pois a imita. Atualmente, o homem, pela techné, imita de forma acelerada a natureza, refaz seus ciclos, apressa sua dinâmica para atender as necessidades atuais de recursos. Além da agricultura e silvicultura, que aceleram o ciclo natural das plantas, muitos outros exemplos podem ilustrar a relação da techné com a physis.

As usinas de dessalinização imitam de forma acelerada o ciclo hidrológico (sobretudo a evaporação e a precipitação) para extrair o sal da água do mar e torná-la potável, como ocorreria naturalmente. A pecuária, as atividades grangeiras e todo tipo de criação imita de forma acelerada o ciclo cicardiano dos animais para aumentar a produção. Na mineração, a extração de argila para a produção de cerâmica e porcelana se faz pela reprodução do ciclo natural das rochas: o desmonte hidráulico imita aceleradamente a desagregação e ero- 
são; a decantação artificial imita também de maneira acelerada a sedimentação da argila em corpos d'água. Nos represamentos para fins energéticos, a techné se impõe no perfil longitudinal de um rio para imitar o que seria um desnível natural, aumentando artificialmente o gradiente fluvial e, consequentemente, a energia cinética necessária para gerar a energia elétrica.

Sistemas técnicos à parte, o que há realmente de novo criado pelo homem?

\section{A escala: um aspecto essencial na análise geográfica do ambiente}

Além da necessária articulação das dimensões social e natural na análise geográfica que nos leva a alguns ajustes conceituais, a escala é um aspecto fundamental para os estudos do meio ambiente. Tomemos como exemplo a floresta amazônica. Além do tipo de uso, a escala do uso pode ser determinante na renovabilidade ou não da floresta. Uma clareira ou uma estrada com pouco tráfego, pela sua escala, permite renovabilidade. Já, uma área de milhares de hectares teria a renovabilidade diminuída até o ponto de não ser mais possível uma restauração da floresta por falta de material genético.

Finalmente, há que se rever a relação direta que se
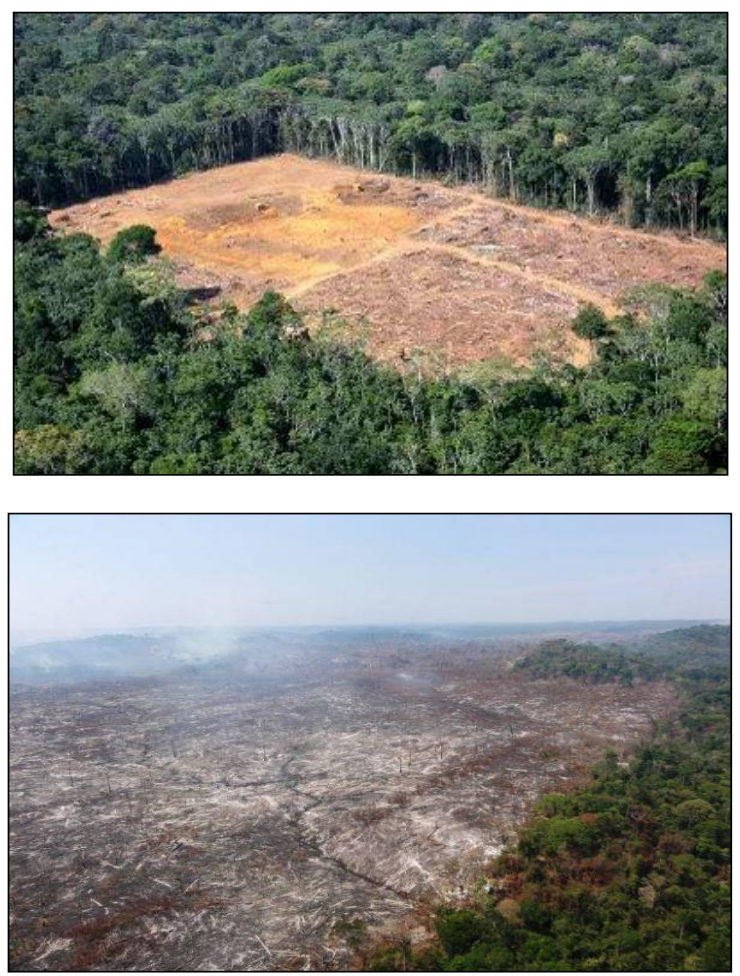

Figura 7 - Duas escalas de desmatamento, alterando o potencial de renovabilidade da floresta.

Fonte: http://www.google.com.br/imgres faz entre recursos não renováveis e recursos esgotáveis, normalmente usados equivocadamente como sinônimos. Há recursos que, embora não sejam renováveis na escala de tempo humano, são inesgotáveis, dadas as quantidades existentes. Seria inconcebível considerar as matérias brutas (rochas britadas, areia etc) usadas na construção civil como esgotáveis, dado que são a constituição básica do planeta; ou o alumínio, o ferro, o quartzo. O sal marinho, embora mineral, é inesgotável e, mais ainda, renovável na escala do tempo humano e até mesmo reprodutível, a exemplo das salinas potiguares.

Enfim, não há como considerar recurso não reno-

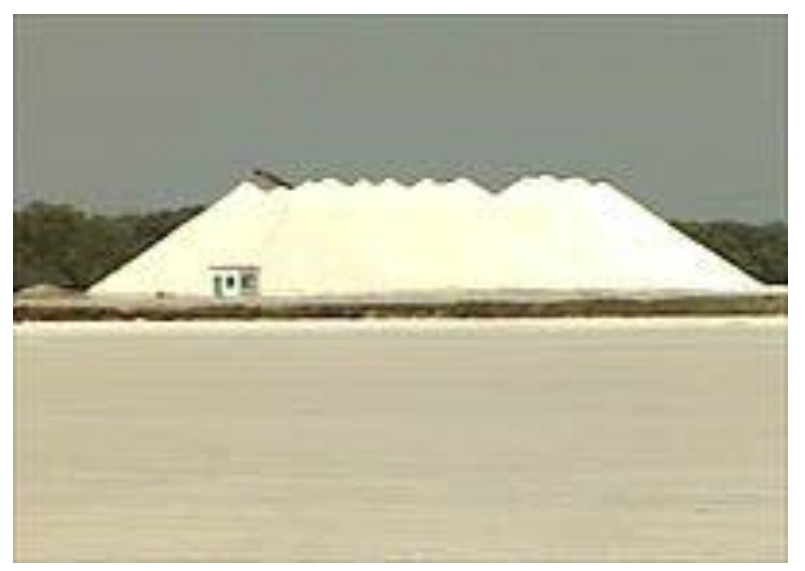

Figura 8 - Nem todo recurso mineral é esgotável, ou não renovável, a exemplo do sal marinho. Macau (RN).

Disponível em: http://www.tvcultura.com.br/ aloescola/ciencias/maravista/4/4mar4.htm

vável como sinônimo de esgotável; ou renovável como sinônimo de inesgotável. A própria floresta, a priori renovável, pode-se esgotar a depender da escala e da intensidade de uso; já os solos, a priori esgotáveis, podem se renovar indefinidamente a depender do tipo e intensidade do uso.

Outro equívoco comum é considerar recurso renovável e inesgotável como sinônimos, e isto sempre ocorre quando se consideram as energias solar e eólica. É insensato considerá-las como renováveis, já que não faria sentido pensar em "reposição de estoques na escala do tempo humano". Será que estaríamos explorando essas energias num ritmo maior do que elas poderiam se recompor? Esta indagação é desprovida de valor; é adequada apenas para recursos renováveis, mas não para estas energias. Assim, classificar estas fontes de energia como inesgotáveis seria conceitualmente mais correto do que renováveis.

Em relação aos recursos hídricos, eles merecem um capítulo à parte. Aqui, limitamo-nos a duas observações: a primeira refere-se ao fato de a água ser tratada como recurso renovável. Isto só seria possível sob uma pers- 
pectiva fragmentada que separa as águas continentais das águas oceânicas. Elas fazem parte de um sistema único que se retroalimenta. Portanto, a visão sistêmica mais uma vez é aqui exigida. E como as quantidades de água não mudam de forma significativa na escala do tempo humano, não há sentido em considerá-la como recurso renovável. $\mathrm{O}$ fato de a água mudar de lugar e de estado faz com que ela deva ser considerada como um recurso naturalmente reciclável. O ciclo hidrológico faz com que as mesmas moléculas de água, mais cedo ou mais tarde, mudem de estado e de reservatório. Toda a água usada pelo homem volta para o sistema, ainda que seu estado possa estar alterado. Por esta razão, alguns autores propõem que o Homem não usa a água do sistema, mas "empresta-a". Camp e Heath-Camp (2009, p.162) explicam que:

Almost all water withdrawn from the hydrologic cycle eventually returns to the cycle. In reality, almost any use is temporary, so "borrowed" might be a more accurate description of what happens to water. ${ }^{6}$

Além disso, atualmente produz-se água potável em escala industrial nas usinas de dessalinização de águas oceânicas, de modo que se pode considerar a água como um recurso natural reprodutível, assim como a agricultura e a mineração.

Com estes questionamentos, propusemos uma revisão conceitual que cremos ser necessária, dados os contextos contemporâneos relacionados à apropriação e exploração dos recursos naturais da Terra, lembrando que estes ajustes podem servir para outros conceitos como impacto, patrimônio, conservação, entre outros. Basta que exercitemos a análise integrada sob a perspectiva sistêmica.

\section{Considerações finais}

A ciência, ao mesmo tempo em que ajuda a transformar o mundo, corre atrás dele para tentar compreendê-lo. Estamos no presente com um olhar para o futuro e outro para o passado. O futuro mostra-nos novos contextos que nos exigem ajustes conceituais, já que a realidade empírica muda mais velozmente do que o pensamento teórico. O olhar para o passado permite-nos resgatar as estruturas da análise geográfica, integrada, dinâmica e sistêmica, com a qual poderemos compreender os contextos atuais e futuros. Pouco de novo existe e as bases da Geografia ainda nos servem e nos são úteis para explicar contextos em diferentes escalas, tempos e lugares. É apenas uma questão de resgate e reorganização do pensamento, sempre fundamentado em exemplos

6 Quase toda a água retirada do ciclo hidrológico, no final, retorna para o ciclo. Na realidade, quase todo uso é temporário, então "emprestada" pode ser uma descrição mais acurada do que ocorre com a água. empíricos, pois toda estrutura teórica deve encontrar seu correlato na realidade; do contrário ela se transformaria em teoremas, característicos das ciências formais. E a temática dos recursos naturais tem demonstrado ser muito eficaz para a reunificação da Geografia em torno das dimensões sociais e naturais. O estudo do ambiente é uma grande oportunidade para o Geógrafo se reorganizar articulando resiliência ecológica, bem-estar social e subsistência econômica. Ainda que a Geografia enquadre-se, na maioria dos departamentos, no rol das ciências humanas, o Homem só pode ser compreendido enquanto ser social se for considerado o contexto em que se insere. Ortega Y Gasset afirmou que "O Homem é ele e suas circunstâncias", e essas circunstâncias, para a Geografia, são sociais e naturais.

\section{Referências}

BEAUMONT, Peter; PHILO, Chris. Environmentalism and Geography - the great debate? In: MATHEWS, John A. e HERBERT, David T. Unifying Geography: common heritage, shared future. Oxfordshire: Routledge, 2004.

BECKER, Bertha K.A geopolítica na virada do milênio: logística e desenvolvimento sustentável. n: CASTRO, I.E.; GOMES, P.C.C.; CORRÊA, R.L. Geografia: conceitos e temas. 12 ed. Rio de Janeiro: Bertrand Brasil, 2009.

BOYLE, Godfrey (ed.). Renewable Energy: power for a sustainable future. 2nd ed. Oxford: Oxford University Press, 2004.

CAMP, William G. e HEATH-CAMP, Betty. Managing Our Natural Resources. Nova Iorque: DelmarCencage Learning, 2009.

CLAVAL, Paul. "A paisagem dos geógrafos". In: CORREAA, R.L. e ROSENDAHL, Z. Paisagens, textos e identidade. Rio de Janeiro: Eduerj, 2004.

EVERETT, Bob et al. Energy Systems and Sustainability. Power for a sustainable future. Oxford: Oxford University Press, 2003.

GODARD, Olivier. 'Gestão Integrada dos Recursos Naturais e do Meio Ambiente: conceitos, instituições e desafios de legitimação. (In.: VIEIRA e WEBER, 2002)

JAKOB, Michael. Le paysage. Paris: Infolio, 2008.

LA BLACHE, Vidal de. Atlas Général.

LEFF, E. Epistemologia Ambiental. São Paulo: Ed. 
Cortez, 2001.

MATHEWS, John A. e HERBERT, David T. Unifying Geography: common heritage, shared future. Oxfordshire: Routledge, 2004.

MONTEIRO, C.A.F. 'Geografia e Ambiente'. Revista do IG - USP, n.5 (Série Orientação). São Paulo, 1984.

MORAES, A.C.R. Meio ambiente e Ciências Humanas. São Paulo: Hucitec, 1994. P.47.

PARK, Chris. Dictionary of Environment and Conservation. Oxford: Oxford University Press, 2011.

RIBEIRO, Wagner Costa. Teorias socioambientais: em busca de uma nova sociedade.

São Paulo: Revista do IEA - USP, n.24, 2010.

SANTOS, M. Espaço e Método. São Paulo: Nobel, 1985.

VENTURI, L.A.B. Le lien retrouvé. Revista Eletrônica Confins, n.6, 2009. http://www.confins.revues.org/ index $5898 . \mathrm{html}$

VENTURI, L.A.B. Recurso Natural: a construção de um conceito. Revista GEOUSP, n. 20. São Paulo, 2007.

VENTURI, L. A. B. The false antagonism between renewable and stock resources and water as an inexhaustible one. Artigo submetido (prelo).

VIEIRA, Paulo Freire \& WEBER, Jacques (orgs.). Gestão de Recursos Naturais Renováveis e Desenvolvimento: novos desafios para a pesquisa ambiental. 3 ed. São Paulo: Cortez, 2002.

VITTE, Antonio Carlos e Guerra, Antonio José Teixeira (orgs.). Reflexões sobre a Geografia Física no Brasil. Rio de Janeiro: Bertrand Brasil, 2004.

ZIMMERMANN, E.W. (1966) Introducción a los recursos mundiales. Barcelona: Oikos-Tau. 